\title{
Not Every Gestational Diabetes is Mellitus!
}

\section{Z Z Ameen, S Bellary}

Diabetes and Endocrinology Department, Heart of England NHS Foundation Trust, Heartlands hospital, Birmingham, UK

\section{CASE HISTORY}

- 21 year old primigravida

- 3 days post-partum

- Traumatic labour / Instrumental delivery

- Severe post-partum haemorrhage - 3 litres blood loss

- 5 units blood transfusion and 2 units FFP

- No problem with Lactation / Breast feeding

\section{ENDOCRINE REFERRAL}

- Polyuria and polydipsia

- Average urine output $500 \mathrm{ml} /$ hour (10-12L / day)

- Drinking around 10 jugs of water a day

- Bedside observations were stable

- Capillary blood glucose level was $4.7 \mathrm{mmol} / \mathrm{L}$

\section{PRE-PARTUM HISTORY}

- 2 weeks history of polyuria and polydipsia prior to labour, but patient thought it was pregnancy-related and never thought to seek any medical advice for it.

\section{INVESTIGATIONS}

\begin{tabular}{|l|l|l|}
\hline Tests & Results & Normal values \\
\hline Lab glucose & $4.9 \mathrm{mmol} / \mathrm{L}$ & $3.9-6.1$ \\
\hline Sodium & $146 \mathrm{mmol} / \mathrm{L}$ & $132-142$ \\
\hline Potassium & $3.9 \mathrm{mmol}$ & $3.5-5.5$ \\
\hline Urea & $6.4 \mathrm{mmol} / \mathrm{L}$ & $2.5-7.5$ \\
\hline Creatinine & $78 \mathrm{Mmol} / \mathrm{L}$ & $46-92$ \\
\hline Corr. Calcium & $2.36 \mathrm{mmo} / \mathrm{L}$ & $2.2-2.6$ \\
\hline TSH & $2.63 \mathrm{ml} / \mathrm{L}$ & $0.25-4.5$ \\
\hline Cortisol & $557 \mathrm{nmol} / \mathrm{L}$ & $200-650$ \\
\hline Plasma osmolality & $296 \mathrm{mosm}$ & $275-295$ \\
\hline Urine osmolality & $78 \mathrm{mosm}$ & $300-1000$ \\
\hline Urinary sodium excretion & $24 \mathrm{mmol}$ & \\
\hline Prolactin & $2630 \mathrm{mU} / \mathrm{L}$ & $102-496$ \\
\hline
\end{tabular}

\section{DIAGNOSIS}

\section{Gestational Diabetes Insipidus (GDI)}

- Symptoms during the $3^{\text {rd }}$ trimester: polyuria and polydipsia

- Passing a large volume $(>3 \mathrm{~L} / 24 \mathrm{~h})$ of diluted urine (osmolality $<300 \mathrm{mOsmol} / \mathrm{kg}$ )

\section{MANAGEMENT AND RECOVERY}

- 1 mcg IM-DDAVP: Good response

- Allowed to drink freely

- Strict monitoring of fluid balance and U\&Es

- Oral Desmopressin (only for one day)

- Full recovery on day 5 post-partum

- Urine output reduced to $2420 \mathrm{ml} / 24 \mathrm{~h}$

- Serum sodium down to $136 \mathrm{mmol} / \mathrm{L}$

- Discharged - GP follow up in 2 weeks: no symptoms

\section{GESTATIONAL DIABETES INSIPIDUS}

- A rare pregnancy-related endocrinopathy

- Affects 1 in 30,000 pregnancies

- First reported cases by the Italian E. Momigliano in 1929 (31 cases of pregnancy-related diabetes insipidus)

- May occur in an apparently healthy woman, during any stage of pregnancy, usually during the $3^{\text {rd }}$ trimester

- Excessive placental vasopressinase in $3^{\text {rd }}$ trimester which breaks down ADH

- Transient, resolves after delivery of the placenta (may last around 4-6 weeks following labour)

- Can be associated with pre-eclampsia, HELLP syndrome and acute fatty liver

- May recur in subsequent pregnancies

- An abrupt change in the voiding pattern during the last trimester of pregnancy manifesting as hypotonic polyuria, and excessive water intake represent the hallmark of the disease

- Most cases can be treated with desmopressin

- Hydrochlorthiazide is the $2^{\text {nd }}$ line if resistant to DDAVP

- If untreated can lead to significant morbidity and mortality (rapid onset hypernatraemia leading to central pontine demyelination and baby's death)

\section{CONCLUSION AND LEARNING POINTS}

- This was an unusual case of Gestational Diabetes Incipidus

- Frequently under-diagnosed because polyuria is often considered normal during pregnancy

- Excessive placental vasopressinase in 3rd trimester which breaks down ADH

- Can be associated with pre-eclampsia, HELLP syndrome and acute fatty liver

- It's very important to diagnose and treat GDI early because it can lead to significant morbidity and mortality (rapid onset hypernatraemia leading to central pontine demyelination and baby's death).

\section{REFERENCES}

-Krege J et al, Obstet Gynecol Surv. 1989 Nov;44(11):789-95.

-Ananthakrishnan S, Endocr Pract. 2009 May-Jun;15(4):377-82

- Jacques A. Durr, N Engl J Med 1987; 316:1070-1074

-Renela Gambito et al,Case Reports in Nephrology (2012)

-Nikolay Aleksandrov et al, Journal of Obs, MARCH 2010

- Carmen Emanuela Georgescu (2011), Diabetes Insipidus, Prof. Kyuz

Kamoi (Ed.), ISBN: 978-953-307-367-5

-Sainz Bueno JA et al, Eur J Obstet Gynecol Reprod Biol

$2005 ; 118: 251-4$ 